Received 00th January 20xx, Accepted 00th January 20xx DOI: $10.1039 /$ x0xx00000x

\title{
Evaluation of the supramolecular interaction of Congo red with cucurbiturils using mass spectrometry and spectroscopic methods ${ }^{\dagger}$
}

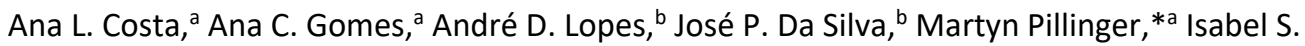 \\ Gonçalves ${ }^{a}$ and J. Sérgio Seixas de Melo*c
}

The ability of cucurbit $[n]$ urils (CB[n]) to decolourise aqueous solutions of the azo dye Congo red (CR) was described more than a century ago alongside the first synthesis of $\mathrm{CB}[n]$. No subsequent studies of the nature of the physical interactions have been reported despite the interest in using $\mathrm{CB}[n]$ as adsorbents for the removal of $\mathrm{CR}$ and related organic dyes from wastewaters. In the present work the supramolecular interaction between $\mathrm{CB}[n](n=7,8)$ and CR was studied by electrospray ionisation mass spectrometry (ESI-MS), ${ }^{1} \mathrm{H}$ NMR, and solid-state characterisation of isolated complexes. Under positive ESI, the formation of host-guest complexes in the gas phase was not observed, suggesting that CR anions do not interact with the portals and the nonpolar inner cavity of the $\mathrm{CB}[n]$ molecules. Conversely, under negative ESI, 1:1 and higher order (1:2, 2:1, 3:1 and 2:2) $\mathrm{CR}: \mathrm{CB}[7]$ and $\mathrm{CR}: \mathrm{CB}[8]$ adducts were detected, which is attributed to interaction between $\mathrm{CR}$ and the outer surface hydrogens of $\mathrm{CB}[n]$. Solid-state supramolecular adducts between $\mathrm{CB}[n]$ and $\mathrm{CR}$ were isolated from aqueous media under either ambient conditions, giving structures denoted as $\mathrm{CR} @ \mathrm{CB}[n](\mathrm{RT})$, or hydrothermal $\left(100{ }^{\circ} \mathrm{C}\right)$ conditions, giving structures denoted as CR@CB[n](100). The adducts were characterised by elemental and thermogravimetric analyses (TGA), powder X-ray diffraction (PXRD), and spectroscopic methods (FT-IR, FT-Raman, ${ }^{13} \mathrm{C}\left\{{ }^{1} \mathrm{H}\right\} \mathrm{CP}$ MAS NMR, UV/Vis and near-IR absorption, fluorescence excitation and emission). The interaction conditions and acid content of the starting $\mathrm{CB}[n]$ influenced the protonation state of CR molecules. CR@CB[7](RT) contained only unprotonated CR, while CR@CB[8](100) contained exclusively protonated CR (ammonium and azonium/quinoid structures). Other adducts contained mixtures of protonated/unprotonated forms.

\section{Introduction}

Cucurbiturils (CB $[n])$ are macrocyclic molecules composed of $n$ glycoluril units connected by $2 n$ methylene bridges. ${ }^{1-3}$ The symmetrical geometry of the homologues with $n=5-8$ creates a nonpolarisable hydrophobic cavity that is accessed via two identical, highly electronegative portals made from $n$ ureido carbonyls (Fig. 1). CBs are readily prepared from the acidcatalysed condensation reaction of glycoluril and formaldehyde. ${ }^{4}$ The homologue $\mathrm{CB}[6]$ is the favoured reaction product, especially at higher reaction temperatures $\left(>110^{\circ} \mathrm{C}\right)$. Although the isolation of $\mathrm{CB}[6]$ (or possibly a mixture of $\mathrm{CB}[n]$ homologues) was first described in 1905 by Behrend et al. ${ }^{5}$, it was not until the early 1980s that the chemical structure of $\mathrm{CB}[6]$ was elucidated by X-ray crystallography. ${ }^{6}$ The next major advance occurred in the early 2000s with the optimisation of the synthesis conditions (e.g. lower reaction temperatures) to

a. Department of Chemistry, CICECO - Aveiro Institute of Materials, University of Aveiro, Campus Universitário de Santiago, 3810-193 Aveiro, Portugal. E-mail: mpillinger@ua.pt (MP).

b. CCMar, and Department of Chemistry and Pharmacy, FCT, University of the Algarve, P-8005-039 Faro, Portugal.

c. CQC, Department of Chemistry, University of Coimbra, Rua Larga, 3004-535 Coimbra, Portugal. E-mail: sseixas@ci.uc.pt (JSSM).

†Electronic Supplementary Information (ESI) available: General instrumentation details, preparation and/or spectroscopic data for CR and PrCR, full scan and fragmentation ESI-MS spectra, ${ }^{1} \mathrm{H}$ NMR spectra, PXRD patterns, TGA curves, ${ }^{13} \mathrm{C} C P$ MAS NMR spectra and accompanying interpretation. See DOI: 10.1039/x0xx00000x allow the formation of significant amounts of $C B$ homologues (mainly $\mathrm{CB}[5], \mathrm{CB}[7]$, and $\mathrm{CB}[8]$ ) in addition to $\mathrm{CB}[6]$, which could then be separated in pure form using fractional crystallisation and dissolution techniques. ${ }^{7,8}$ Subsequent additions to the $\mathrm{CB}[n]$ family included $\mathrm{CB}[10]$ (as its $\mathrm{CB}[10] \cdot \mathrm{CB}[5]$ inclusion complex and then, later on, in its free form), $, 9,10$ and $C B[13-15]$, which are distinct from the other homologues since they adopt twisted structures. ${ }^{11,12}$
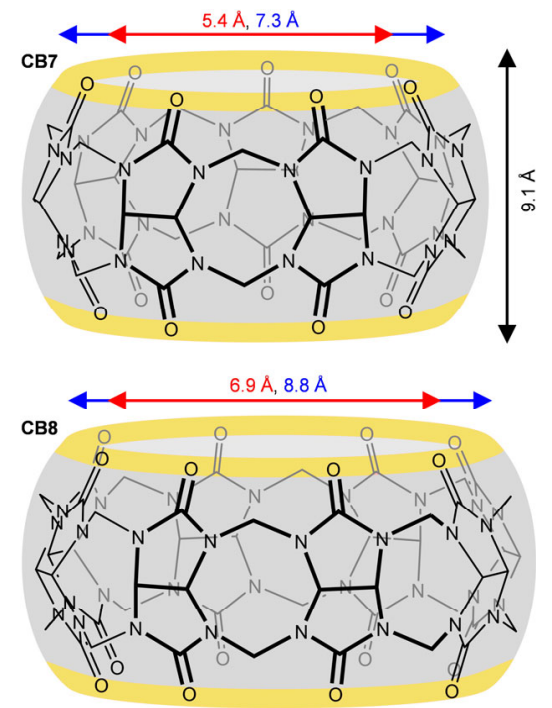

Fig. 1 Structures of $\mathrm{CB}[n]$ showing the portal (red arrow) and cavity (blue arrow) sizes. 
The supramolecular chemistry of $\mathrm{CB}[6]$ was developed in the 1980s and 1990 s by Mock, ${ }^{13}$ Buschmann, ${ }^{14}$ and their coworkers. Extensive guest-binding studies showed that the hydrophobic cavity provides an inclusion site for nonpolar molecules, while the carbonyl-lined portals allow $\mathrm{CB}[6]$ to bind ions and molecules through charge-dipole and hydrogenbonding interactions. ${ }^{15}$ Hence, $\mathrm{CB}[6]$ displays a particular affinity for small organic molecules that combine cationic and hydrophobic subunits in their structure, such as alkylammonium ions. Research on CB supramolecular chemistry increased sharply in the 2000s following the preparation and eventual commercial availability of the homologues $C B[5]-$ $C B[8]$. The larger cavity sizes of $C B[7]$ and $C B[8]$ enable the encapsulation of more bulky guests such as drug molecules, ${ }^{16}$ organometallic compounds, ${ }^{17,18}$ and organic dyes. ${ }^{19,20}$

Apart from host-guest chemistry, two other branches of $\mathrm{CB}$ chemistry allow the construction of supramolecular assemblies and functional materials. The most familiar of these is the interaction of the $\mathrm{CB}$ oxygen atoms with metal ions or clusters. ${ }^{21-23}$ The interaction may involve direct coordination or indirect coordination bridged by coordinated water molecules or clusters (i.e., the $C B$ behaves as an outer-sphere ligand). The other branch of $\mathrm{CB}$ supramolecular chemistry is founded on weak noncovalent outer-surface interactions, such as $\mathrm{C}-\mathrm{H} \cdots \pi$ interactions between $\mathrm{CH}$ groups of glycoluril segments and aromatic rings, $\pi-\pi$ interactions between $\mathrm{CB}$ carbonyl groups and aromatic rings, and ion-dipole interactions between the electrostatically positive outer surface of CBs and inorganic or organic anions. ${ }^{24,25}$ The resultant supramolecular assemblies have been termed exclusion complexes or lattice inclusion compounds. Aromatic molecules that form such assemblies include 4,4', 4' '-benzene-1,3,5-triyl-tribenzoate, ${ }^{26}$ 1-anilino-8naphthalenesulfonate $\quad(1,8-\mathrm{ANS}){ }^{27,28} \quad 1,5$-naphthalenedisulfonate (1,5-NDS), ${ }^{29}$ and 2,6-naphthalenedisulfonate. ${ }^{30}$

Looking back to the pioneering work of Behrend et al., ${ }^{5}$ it is striking to note that even at this early stage they disclosed the ability of the polymeric substance to form cocrystals (complexes) with a variety of substances including $\mathrm{KMnO}_{4}$, $\mathrm{AgNO}_{3}, \mathrm{H}_{2} \mathrm{PtCl}_{6}, \mathrm{NaAuCl}_{4}$, Congo red (CR), and methylene blue. For the azo dye CR (Fig. 2), the authors reported that an aqueous solution of the dye was decolourised upon addition of the polymeric substance, with the formation of a red precipitate. CR was the first of many so-called direct dyes and was a huge commercial success for the dye-manufacturing company AGFA. ${ }^{31,32}$ Although CR was eventually superseded by superior textile dyes, it has found other uses as a $\mathrm{pH}$ indicator ${ }^{33}$ and as a histological stain for amyloid. ${ }^{34}$ In general, however, most of the contemporary research on $C R$ is conditioned by the fact that $C R$ is toxic to many organisms and metabolises to benzidine, a known human carcinogen. ${ }^{35,36}$ Although the marketing to the general public of substances containing CR has been banned in many countries (e.g., since 1999 in the EU), it is still used in some developing countries due to its low cost. Hence, there has been a lot of research on the development of methods for the removal of CR from contaminated wastewater. Adsorption is a proven treatment technology, and a variety of materials have been studied as adsorbents. ${ }^{37}$

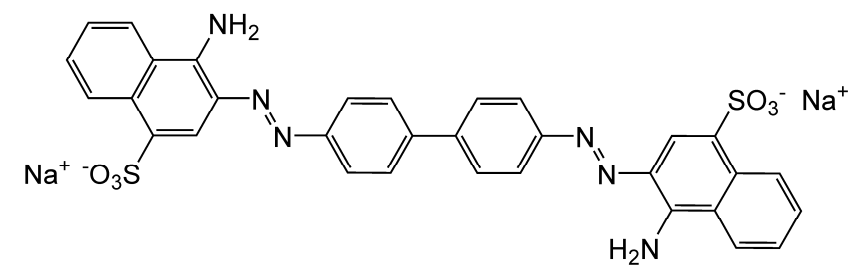

Fig. 2 The chemical structure of the disodium salt of Congo red (CR).

Despite the very early revelation by Behrend et al. that the glycoluril-formaldehyde condensation product (CB[6]) could decolourise an aqueous solution of $C R$, no further studies have been reported on the complexation behaviour of cucurbiturils with $C R$. Such studies may have a wider significance, given the interest in using $\mathrm{CB}[n]$ as adsorbents for the removal of organic dyes from textile wastewaters. ${ }^{38-43}$ Therefore, in the present work, our aim was to achieve a better understanding of complex formation between $\mathrm{CR}$ and $\mathrm{CB}[n](n=7,8)$, using mass spectrometry to detect adduct formation, together with thermal analysis and spectroscopic techniques to characterise the solid complexes that were isolated. The results indicate that in the isolated compounds the CR molecules are trapped within the $\mathrm{CB}[n]$ lattice, with outer-surface interactions being the likely driving force for the supramolecular assembly.

\section{Experimental}

\section{Materials and methods}

Setups for general instrumental methods are described in the $\mathrm{ESI}^{+}$. Hydrochloric acid (37\% Aldrich) and acetone (p.a., Scharlau) were purchased from commercial sources and used as received. Ultrapure water from a Milli-Q water purifying system was used in all the syntheses. Congo red (CR) [sodium salt of 3,3'-([1,1'-biphenyl]-4,4'-diyl)bis(4-aminonaphthalene-1-

sulfonic acid)] was obtained from BDH Chemicals and recrystallised from water:ethanol (1:1) before use. Characterisation data (FT-IR band frequencies, ${ }^{1} \mathrm{H}$ NMR and ${ }^{13} \mathrm{C}\left\{{ }^{1} \mathrm{H}\right\} \mathrm{CP}$ MAS NMR chemical shifts) for $\mathrm{CR}$ and the protonated blue form of $\mathrm{CR}$ (PrCR, prepared as described in the $\mathrm{ESI}^{\dagger}$ ) are given in the $\mathrm{ESI}^{+}$. The preparation and purification of $\mathrm{CB}$ [7] [composition $\mathrm{C}_{42} \mathrm{H}_{42} \mathrm{~N}_{28} \mathrm{O}_{14} \cdot 11 \mathrm{H}_{2} \mathrm{O} \cdot 0.1 \mathrm{HCl} \cdot 0.5\left(\mathrm{CH}_{3} \mathrm{COCH}_{3}\right)$ ] and $\mathrm{CB}$ [8] [composition $\mathrm{C}_{48} \mathrm{H}_{48} \mathrm{~N}_{32} \mathrm{O}_{16} \cdot 7 \mathrm{H}_{2} \mathrm{O} \cdot 3 \mathrm{HCl} \cdot 1.5\left(\mathrm{CH}_{3} \mathrm{COCH}_{3}\right)$ ] were described previously. ${ }^{44,45}$

\section{ESI-MS studies}

ESI-MS spectra were obtained using a Bruker Daltonics HCT ultra mass spectrometer under positive and negative polarity. Sample solutions were prepared by dissolving $\mathrm{CB}[n](n=7$ or 8$)$ and $C R$ in Milli-Q water to give a final concentration of $50 \mu \mathrm{M}$ for each component. The samples were analysed immediately after preparation. The ions were continuously generated by infusing the aqueous solutions at $4 \mu \mathrm{L} \mathrm{min}{ }^{-1}$ into the mass spectrometer ion source, with the help of a syringe pump (KdScientific, model 781100, USA). The ion optics and spray parameters were optimised for the signals of $\mathrm{CR}: \mathrm{CB}[n]$ adducts. Typical experimental conditions under negative polarity were as follows: capillary voltage, $3.2 \mathrm{kV}$; capillary exit voltage, - $300 \mathrm{~V}$; 
skimmer voltage, $-15 \mathrm{~V}$; drying gas, $300^{\circ} \mathrm{C}$ at $6 \mathrm{~L} \mathrm{~min}^{-1}$; nebuliser gas pressure, $40 \mathrm{psi}$. Signal assignments were based on the $\mathrm{m} / \mathrm{z}$ values, isotope distributions and fragmentation patterns.

\section{Photophysical characterisation in the solid-state}

The absorption spectra of solid samples were recorded on a Cary 5000 UV-Vis-NIR spectrophotometer by diffuse reflectance. Before the spectra were obtained, a baseline, with barium sulfate, was collected. The solid-state fluorescence spectra were recorded on a Horiba-Jobin-Ivon SPEX FluoroLog 3-22 spectrofluorimeter using triangular quartz cuvettes. The FluoroLog consists of a modular spectrofluorimeter with double grating excitation (range 200-950 $\mathrm{nm}$, optimised in the UV and with a blazed angle at $330 \mathrm{~nm}$ ) and emission (range $200-950 \mathrm{~nm}$, optimised in the visible and with a blazed angle at $500 \mathrm{~nm}$ ) monochromators. The bandpass for excitation and emission was 0-15 $\mathrm{nm}$ (values that were continuously adjustable using computer software) and the wavelength accuracy was $\pm 0.5 \mathrm{~nm}$. The excitation source consisted of an ozone-free $450 \mathrm{~W}$ Xenon lamp and the emission detector was a Hamamatsu R928 Photomultiplier (200-950 $\mathrm{nm}$ range), cooled with a Products for Research thermoelectric refrigerated chamber (model PC177CE005), or a Hamamatsu R5509-42 (900-1400 nm range), cooled to $193 \mathrm{~K}$ in a liquid nitrogen chamber (Products for Research model PC176TSCE-005), and a photodiode as the reference detector. ${ }^{46}$

\section{Synthesis of CR:CB supramolecular adducts}

Adduct formation between $\mathrm{CB}[n]$ ( $n=7$ or 8 ) and $\mathrm{CR}$ was performed either at $25{ }^{\circ} \mathrm{C}$ in open system (Schlenk tube) or at $100{ }^{\circ} \mathrm{C}$ in a Teflon-lined stainless steel autoclave. The initial $\mathrm{CR}: \mathrm{CB}[n]$ molar ratios were either $1: 1\left(25^{\circ} \mathrm{C}\right)$ or $1.3: 2\left(100^{\circ} \mathrm{C}\right)$.

CR@CB[7](RT). A solution of CR $(0.09 \mathrm{~g}, 0.13 \mathrm{mmol})$ in water $(6 \mathrm{~mL})$ was added to a solution of $\mathrm{CB}$ [7] $(0.18 \mathrm{~g}, 0.13 \mathrm{mmol})$ in water $(10 \mathrm{~mL})$ in a Schlenk tube immersed in a temperaturecontrolled oil bath $\left(25^{\circ} \mathrm{C}\right)$. The mixture was stirred at room temperature for $2 \mathrm{~h}$. The resultant mahogany-coloured solid was separated from the aqueous mother liquor ( $\mathrm{pH} \mathrm{5-6)} \mathrm{by}$ centrifugation, washed with cold water $(2 \times 5 \mathrm{~mL})$, and finally vacuum-dried. Yield: $0.20 \mathrm{~g}$ (68\%, based on $\mathrm{CB}[7])$. Anal. Calcd for $\left(\mathrm{C}_{42} \mathrm{H}_{42} \mathrm{~N}_{28} \mathrm{O}_{14}\right)_{1.15}\left(\mathrm{C}_{32} \mathrm{H}_{22} \mathrm{~N}_{6} \mathrm{Na}_{2} \mathrm{O}_{6} \mathrm{~S}_{2}\right) \cdot 33 \mathrm{H}_{2} \mathrm{O}$ (2628.58): C, 36.69; $\mathrm{H}, 5.23$; N, 20.36. Found: $\mathrm{C}, 36.64 ; \mathrm{H}, 5.02 ; \mathrm{N}, 20.32$. TGA revealed a mass loss of $20.0 \%$ at $230{ }^{\circ} \mathrm{C}$ (calcd for loss of $33 \mathrm{H}_{2} \mathrm{O}$ : $22.6 \%$ ), and a residual mass of $7.2 \%$ at $750{ }^{\circ} \mathrm{C}$ (calcd on the basis of a $1: 0 \mathrm{Na}_{2} \mathrm{CR}$ :PrCR molar ratio: $\left.6.1 \%\right)$.

CR@CB[7](100). A Teflon-lined stainless steel autoclave was charged with CR (0.07 g, $0.10 \mathrm{mmol}), \mathrm{CB}$ [7] $(0.21 \mathrm{~g}, 0.15 \mathrm{mmol})$ and water $(10 \mathrm{~mL})$, and heated in an oven at $100{ }^{\circ} \mathrm{C}$ for $48 \mathrm{~h}$. The resultant dark red solid was separated from the aqueous mother liquor by filtration, washed with water $(5 \mathrm{~mL})$, acetone (5 mL), and finally vacuum-dried. Yield: $0.20 \mathrm{~g}(72 \%$, based on $\mathrm{CB}$ [7]). Anal. Calcd for $\left(\mathrm{C}_{42} \mathrm{H}_{42} \mathrm{~N}_{28} \mathrm{O}_{14}\right)_{1.6}\left(\mathrm{C}_{32} \mathrm{H}_{22.3} \mathrm{~N}_{6} \mathrm{Na}_{1.7} \mathrm{O}_{6} \mathrm{~S}_{2}\right) \cdot 23 \mathrm{H}_{2} \mathrm{O} \quad$ (2965.16): C, 40.18; H, 4.61; N, 24.00. Found: C, 39.99; H, 4.44; N, 23.97. TGA revealed a mass loss of $14.4 \%$ at $200{ }^{\circ} \mathrm{C}$ (calcd for loss of $23 \mathrm{H}_{2} \mathrm{O}$ : $14.0 \%$ ), and a residual mass of $4.6 \%$ at $750{ }^{\circ} \mathrm{C}$ (calcd on the basis of a 0.85:0.15 $\mathrm{Na}_{2} \mathrm{CR}:$ PrCR molar ratio: $4.6 \%$ ).
CR@CB[8](RT). A solution of CR (0.08 g, $0.12 \mathrm{mmol})$ in water $(6 \mathrm{~mL})$ was added to a suspension of $\mathrm{CB}$ [8] $(0.20 \mathrm{~g}, 0.12 \mathrm{mmol})$ in water $(10 \mathrm{~mL})$ in a Schlenk tube immersed in a temperaturecontrolled oil bath $\left(25^{\circ} \mathrm{C}\right)$. The mixture was stirred at room temperature for $24 \mathrm{~h}$. The resultant dark purple solid was separated from the aqueous mother liquor $(\mathrm{pH} 3)$ by centrifugation, washed with cold water $(6 \mathrm{~mL})$, and finally vacuum-dried. Yield: $0.27 \mathrm{~g}(94 \%$, based on $\mathrm{CB}[8])$. Anal. Calcd for $\left(\mathrm{C}_{48} \mathrm{H}_{48} \mathrm{~N}_{32} \mathrm{O}_{16}\right)_{1.05}\left(\mathrm{C}_{32} \mathrm{H}_{23.3} \mathrm{~N}_{6} \mathrm{Na}_{0.7} \mathrm{O}_{6} \mathrm{~S}_{2}\right) \cdot 22 \mathrm{H}_{2} \mathrm{O}$ (2459.98): C, 40.23; $\mathrm{H}, 4.82 ; \mathrm{N}, 22.55$. Found: $\mathrm{C}, 40.04 ; \mathrm{H}, 4.37 ; \mathrm{N}, 22.51$. TGA revealed a mass loss of $16.6 \%$ at $200{ }^{\circ} \mathrm{C}$ (calcd for loss of $22 \mathrm{H}_{2} \mathrm{O}$ : $16.1 \%$ ), and a residual mass of $2.2 \%$ at $750{ }^{\circ} \mathrm{C}$ (calcd on the basis of a 0.35:0.65 $\mathrm{Na}_{2} \mathrm{CR}: \mathrm{PrCR}$ molar ratio: $2.3 \%$ ).

CR@CB[8](100). A Teflon-lined stainless steel autoclave was charged with $\mathrm{CR}(0.07 \mathrm{~g}, 0.10 \mathrm{mmol}), \mathrm{CB}[8](0.25 \mathrm{~g}, 0.15 \mathrm{mmol})$ and water $(10 \mathrm{~mL})$, and heated in an oven at $100^{\circ} \mathrm{C}$ for $48 \mathrm{~h}$. The resultant reddish-purple solid was separated from the aqueous mother liquor by filtration, washed with water $(10 \mathrm{~mL})$, and finally vacuum-dried. Yield: $0.20 \mathrm{~g}(62 \%$, based on $\mathrm{CB}[8])$. Anal. Calcd for $\left(\mathrm{C}_{48} \mathrm{H}_{48} \mathrm{~N}_{32} \mathrm{O}_{16}\right)_{1.3}\left(\mathrm{C}_{32} \mathrm{H}_{24} \mathrm{~N}_{6} \mathrm{O}_{6} \mathrm{~S}_{2}\right) \cdot 19 \mathrm{H}_{2} \mathrm{O}$ (2722.82): C, 41.64; $\mathrm{H}, 4.61 ; \mathrm{N}, 24.49$. Found: $\mathrm{C}, 41.63 ; \mathrm{H}, 4.43 ; \mathrm{N}, 24.41$. TGA revealed a mass loss of $10.4 \%$ at $230{ }^{\circ} \mathrm{C}$ (calcd for loss of $19 \mathrm{H}_{2} \mathrm{O}$ : $12.5 \%)$, and a residual mass of $0 \%$ at $750{ }^{\circ} \mathrm{C}$.

\section{Results and Discussion}

\section{ESI-MS and ${ }^{1} \mathrm{H}$ NMR studies}

The supramolecular interaction between cucurbiturils and CR was first evaluated by ESI-MS. ESI-MS has been used to study the formation of cucurbituril host-guest complexes ${ }^{47}$ and their aggregates $^{48}$ as well as the interaction between negative ions and the outer surface hydrogens of these molecular containers. ${ }^{49}$ Initially, the formation of complexes between CR and both macrocycles under positive polarity was evaluated. $C R$ and $\mathrm{CB}[n]$ were dissolved in water $(50 \mu \mathrm{M} C R, 50 \mu \mathrm{M} \mathrm{CB}[n])$ and the solutions analysed immediately. The main signals observed were assigned to free hosts and aggregates of free hosts (Fig. S1 in the $\mathrm{ESI}^{+}$). The absence of signals corresponding to host-guest complexes under positive ESI suggests that CR is not interacting with the inner cavity of the studied cucurbiturils.

To obtain further insights into the interaction between $C R$ and $\mathrm{CB}[n]$, the formation $\mathrm{CR} @ \mathrm{CB}[7]$ complexes was studied by ${ }^{1} \mathrm{H}$ NMR. CB[7] gave the expected ${ }^{1} \mathrm{H}$ NMR signals, while $\mathrm{CR}$, as reported, ${ }^{50}$ showed weak and broad signals (Fig. S2 in the ESI ${ }^{\dagger}$ ). After addition of $\mathrm{CR}$ to $\mathrm{CB}$ [7] at 1:1 stoichiometry (1 mM) CR signals were not detected and $\mathrm{CB}$ [7] peaks broadened (Fig. S2). No signals assignable to $\mathrm{CR}-\mathrm{CB}[7]$ interaction were detected by ${ }^{1} \mathrm{H}$ NMR. Unlike that observed for CR@cyclodextrins, ${ }^{50} \mathrm{CB}[7]$ does not sharpen $C R$ signals. In fact, a precipitate was observed inside the NMR tube, which explains the absence of CR peaks and indicates that $\mathrm{CB}[7]$ is interacting with $\mathrm{CR}$ leading to its precipitation. Similar behaviour was observed for 1,8-ANS and $\mathrm{CB}[n](n=6,7) \cdot{ }^{27,28}$ For $\mathrm{CB}[7]$, a $2: 1$ complex with 1,8 -ANS sandwiched between the outer surface of two $\mathrm{CB}[7]$ was proposed. ${ }^{28}$ Liu et al. described a similar type of supramolecular framework with 1,5-NDS anions interacting with $\mathrm{CB}[6]$ through hydrogen bonding. ${ }^{51}$ 


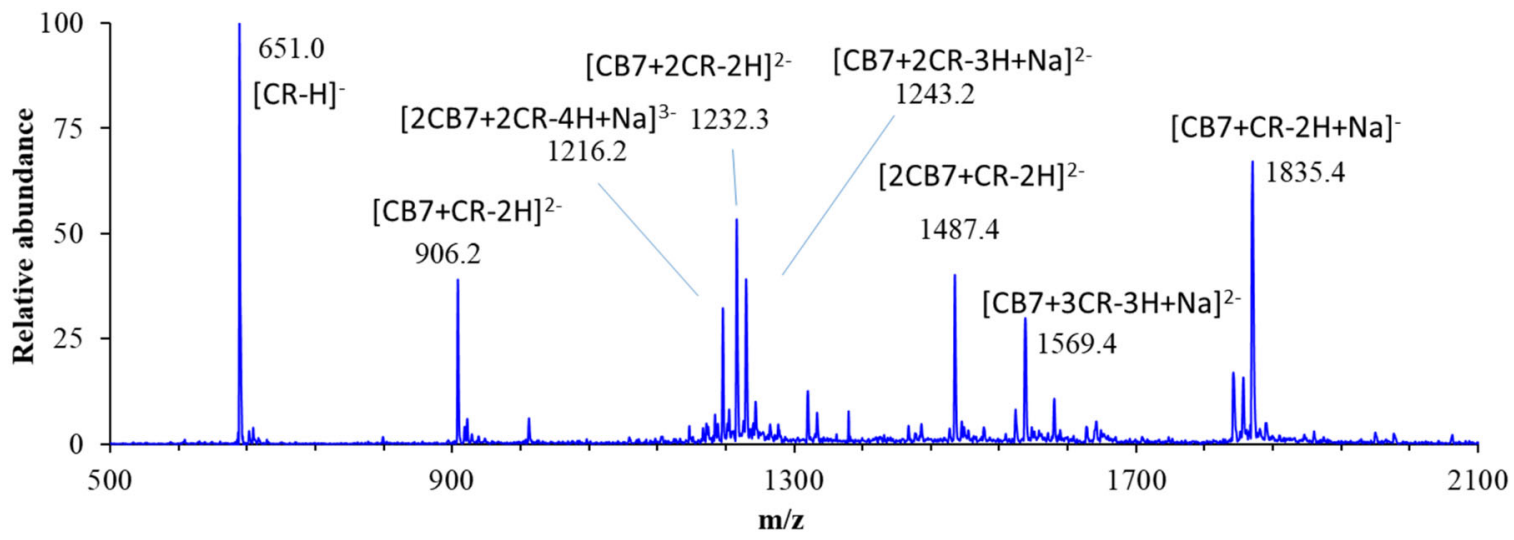

Fig. 3 Full scan spectrum of aqueous solutions of CR@CB[7] (50 $\mu \mathrm{M}: 50 \mu \mathrm{M})$ under negative ESI. The $m / z$ values are of the first peak of the isotope series.

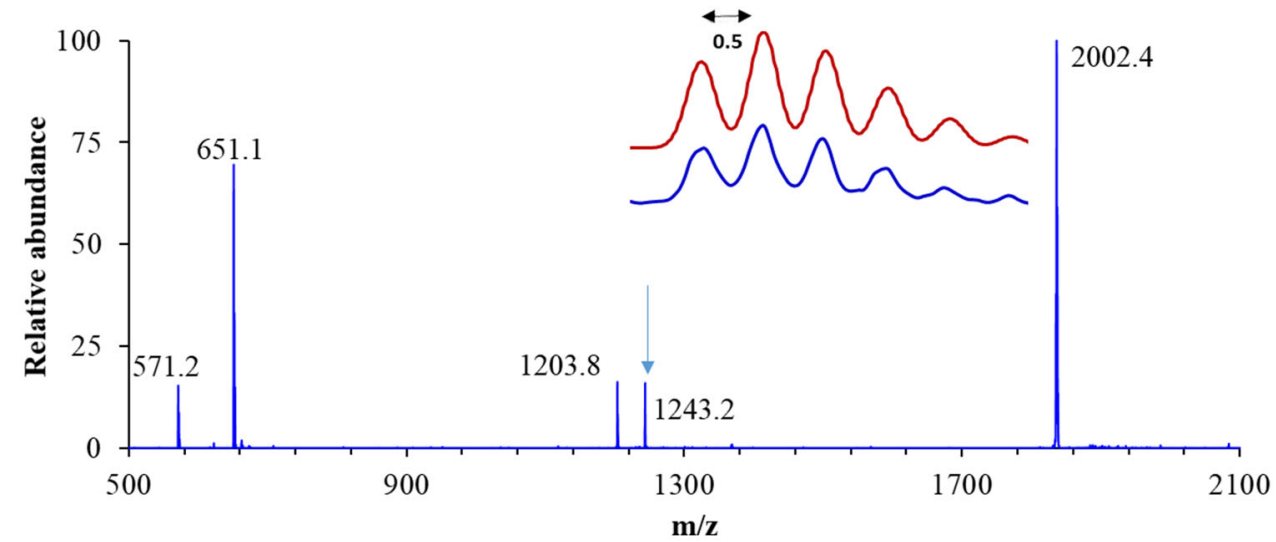

Fig. 4 Fragmentation spectrum (MS²) of $m / z$ 1243.2. The arrow indicates the fragmented peak. The insert shows the experimental (blue) and simulated (red) isotope distributions.

To evaluate the possible interaction between $\mathrm{CR}$ anions and the outer surface hydrogens of $\mathrm{CB}[n]$ we studied the formation of complexes/aggregates under negative ESI. Interaction between $\mathrm{CB}[n]$ and anions has been observed under negative ESI and associated with interactions with the outer surface hydrogens of $\mathrm{CB}[n] .{ }^{49} \mathrm{CR}: \mathrm{CB}[7]$ and $\mathrm{CR}: \mathrm{CB}[8]$ adducts are readily observed in the gas phase after analysis of aqueous solutions containing $50 \mu \mathrm{M} \mathrm{CR}$ and $50 \mu \mathrm{M} \mathrm{CB}[n]$ (Fig. 3 and Fig. S3 in the $\mathrm{ESI}^{+}$). Signal assignments were based on the $m / z$ values, isotope distributions and fragmentation patterns (see, for example, Fig. 4, which shows the fragmentation spectrum for $\mathrm{m} / \mathrm{z}$ 1243.2). Besides 1:1 (CR:CB[n]) adducts, higher order aggregates, namely 1:2, 2:1, 3:1 and 2:2, were observed. We cannot exclude the presence in the solutions of aggregates with even higher order. They might have $m / z$ values higher than the upper limit of the instrument used or, most likely, be destroyed during the electrospray. The formation of $\mathrm{CR}-\mathrm{CB}[n]$ aggregates must be due to interaction between $C R$ anions and the outer surface hydrogens of $\mathrm{CB}[n]$.

\section{Isolation and characterisation of CR@CB[n] adducts}

To isolate CR@CB[n] adducts, a solution of CR in water was added to either a solution (CB[7]) or a solution/suspension ( $C B[8])$ of the cucurbituril in water, with the $\mathrm{CR:CB}[n]$ molar ratio being set at $1: 1$, and the reaction mixtures were stirred at room temperature (RT) for either $2 \mathrm{~h}$ (for $\mathrm{CB}[7]$ ) or $24 \mathrm{~h}$ (for
$\mathrm{CB}[8])$. The resultant suspensions were centrifuged to isolate a mahogany-coloured solid in the case of CR@CB[7](RT) and a dark purple solid in the case of CR@CB[8](RT). PXRD analysis indicated that both solids had amorphous character, with only three very broad peaks being present in the $2 \theta$ range of $5-30^{\circ}$ (Fig. S4 in the $\mathrm{ESI}^{+}$). In an effort to improve the crystallinity of the compounds, a second set of reactions was performed in which a $50 \%$ excess of $\mathrm{CB}[n]$ was used $(\mathrm{CR}: \mathrm{CB}[n]=1.3: 2)$ and the mixtures were subjected to a hydrothermal treatment at $100{ }^{\circ} \mathrm{C}$ for $48 \mathrm{~h}$ in a Teflon-lined stainless steel autoclave. The PXRD pattern of the dark red $\mathrm{CB}[7]$ solid product, denoted $C R @ C B[7](100)$, was unchanged from that for $C R @ C B[7](R T)$, while the pattern for the reddish-purple $\mathrm{CB}[8]$ solid product, CR@CB[8](100), displayed several fairly narrow reflections in the $2 \theta$ range of $5-30^{\circ}$ characteristic of a microcrystalline structure (Fig. S4). These reflections do not match with those of the as-prepared $\mathrm{CB}[8]$ sample nor with those present in previously reported experimental or computed diffractograms for $\mathrm{CB}[8]$ hydrate phases, ${ }^{45}$ indicating that the $\mathrm{CB}$ molecules in $\mathrm{CR} @ \mathrm{CB}[8](100)$ adopt a different crystal packing arrangement. None of the PXRD patterns for the CR@CB $n]$ adducts display peaks assignable to a pure (bulk) CR phase, suggesting that the isolated solids are not physical mixtures of $\mathrm{CB}[n]$ and $\mathrm{CR}$ phases.

Elemental analyses (CHN) indicated final $\mathrm{CB}[n] / \mathrm{CR}$ molar ratios of 1.15 for $C R @ C B[7](R T), 1.05$ for $C R @ C B[8](R T), 1.6$ for CR@CB[7](100), and 1.3 for CR@CB[8](100). Water contents 
were estimated from the TGA weight losses between room temperature and $200-230{ }^{\circ} \mathrm{C}$ ( Fig. S5 in the $\mathrm{ESI}^{+}$). Apart from the different initial weight losses due to the variable water contents, the TGA curves for CR@CB[7](100) and CR@CB[8](100) almost overlapped, with the onset of decomposition being at about $300^{\circ} \mathrm{C}$. Decomposition took place in two consecutive steps identified by DTG $_{\max }$ (DTG = derivative thermogravimetric) values of 400 and $500{ }^{\circ} \mathrm{C}$. The $\mathrm{CB}[n]$ molecules in these two adducts seem to possess slightly higher thermal stability than the pure as-prepared $\mathrm{CB}$ [7] and $\mathrm{CB}[8]$ samples, which displayed $\mathrm{DTG}_{\max }$ values of $380 \pm 5{ }^{\circ} \mathrm{C}$. Pure $\mathrm{CR}$ decomposes in two steps up to $535{ }^{\circ} \mathrm{C}$ with the abrupt mass losses giving DTG max values of 315 and $492^{\circ} \mathrm{C}$ (Fig. S5). Based on the elemental compositions proposed for the isolated $\mathrm{CR} @ \mathrm{CB}[n]$ solids and the observation of a $12.9 \%$ mass loss for the first step in the TGA curve of pure $C R$, a mass loss step of 3.0-3.6\% would be expected to be present at ca. $315^{\circ} \mathrm{C}$ in the TGA curves of CR@CB[n] if the solids were physical mixtures rather than true supramolecular adducts. No such step was visible in any of the curves. As found for CR@CB[n](100), the TGA curves for CR@CB[n](RT) are very similar. However, despite the fact that these compounds start to decompose at a similar temperature to that for $\mathrm{CR} @ \mathrm{CB}[n](100)$ (ca. $300{ }^{\circ} \mathrm{C}$ ), decomposition of the organic components in $\mathrm{CR} @ \mathrm{CB}[n](\mathrm{RT})$ takes place over a wider temperature range (up to $700{ }^{\circ} \mathrm{C}$ ), with a final step being observed with $D T G_{\max }=615 \pm 5^{\circ} \mathrm{C}$.

The residual masses registered at $750{ }^{\circ} \mathrm{C}$ by TGA are different for each of the $\mathrm{CR} @ \mathrm{CB}[n]$ adducts, decreasing in the order $\mathrm{CR} @ \mathrm{CB}[7](\mathrm{RT})$ (7.2\%) > CR@CB[7](100) (4.6\%) > CR@CB[8](RT) (2.2\%) > CR@CB[8](100) (0\%). The residue obtained from the thermal decomposition of pure CR $(23 \%$ mass at $750{ }^{\circ} \mathrm{C}$ ) is composed mainly of $\mathrm{Na}_{2} \mathrm{SO}_{4} \cdot{ }^{52}$ As will be discussed below, the different residual $\mathrm{Na}_{2} \mathrm{SO}_{4}$ masses recorded in the TGA curves of the $\mathrm{CR} @ \mathrm{CB}[n]$ adducts can be attributed to the presence of the anionic (i.e., disodium salt) and/or protonated (sodium-free) forms of CR in different proportions.

The FT-IR spectra of the adducts CR@CB $[n](R T / 100)$ are dominated by bands due to the CB molecules (Fig. 5). In general, these bands are unshifted relative to those for as-prepared $\mathrm{CB}[7]$ and $\mathrm{CB}[8]$. With reference to the spectrum of CR (Fig. $5(\mathrm{a}))$, the spectra for the adducts present two bands that can be assigned to the azo dye, namely a band at $1043 \mathrm{~cm}^{-1}$ due to the symmetric stretching vibration of the sulfonate group, and a broad absorption centred at $1612 \mathrm{~cm}^{-1}$ assigned to an aromatic ring $\mathrm{C}-\mathrm{C}$ stretching vibration. The relative intensities of these two bands decrease on going from $\mathrm{CR} @ \mathrm{CB}[n](\mathrm{RT})$ to CR@CB[n](100), which is consistent with the elemental analyses that indicate lower $C R$ contents for the latter.

Fig. 6 shows the FT-Raman spectra of the CR@CB[n] adducts in the range of $1000-1800 \mathrm{~cm}^{-1}$. In contrast to the IR spectra, the Raman spectra are dominated by bands due to $C R$. The spectrum for CR@CB[7](RT) (Fig. 6(d)) is essentially identical to that for CR (Fig. 6(a)). On the other hand, additional bands at 1176, 1265 and $1565 \mathrm{~cm}^{-1}$ are present for CR@CB[7](100) (Fig. $6(e))$, which are attributed to a protonated form of CR. The band at $1176 \mathrm{~cm}^{-1}$ appears alongside a more intense band at 1155 $\mathrm{cm}^{-1}$. The latter is assigned to a phenyl- $\mathrm{N}=$ stretching mode of an azoic structure (i.e., unprotonated anionic $\mathrm{CR}$ and/or protonated ammonium form), while the new high-frequency band is assigned to a N-N stretching vibration of a quinoid structure (Scheme 1). ${ }^{33}$ This assignment was confirmed by isolating the protonated form of CR (PrCR), which precipitates as a blue solid upon addition of dilute $\mathrm{HCl}$ to an aqueous solution of $\mathrm{CR}$ ( $\mathrm{pH}<2.7$ ). The Raman spectrum of PrCR (Fig. 6(b)) displays bands at 1179, 1265 and $1565 \mathrm{~cm}^{-1}$, which are in accordance with the new bands observed for CR@CB[7](100).

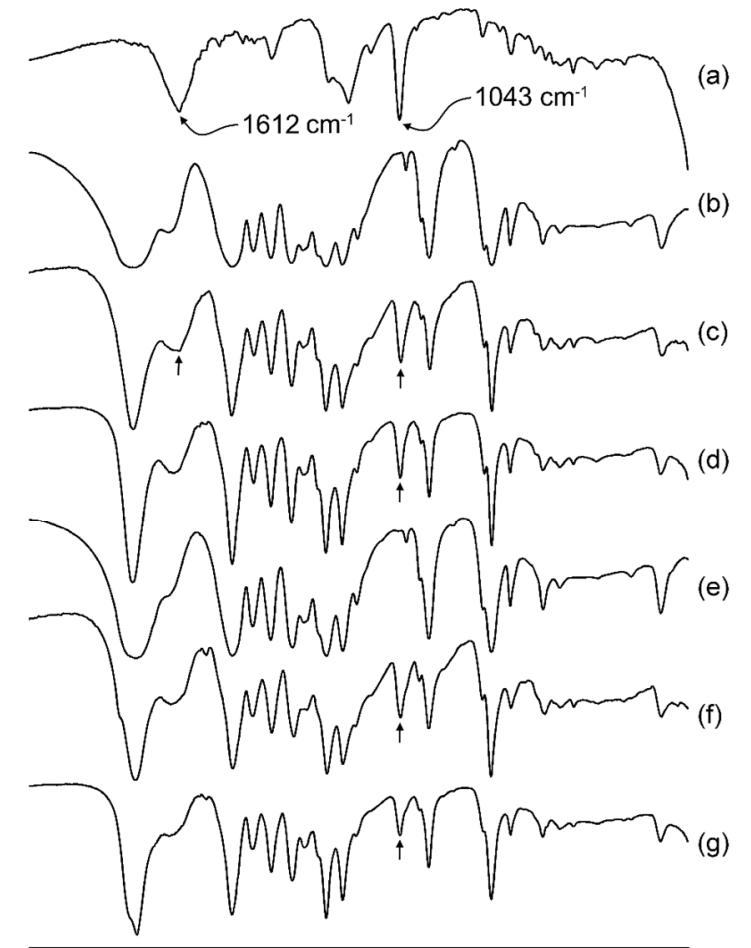

$2000 \quad 1800 \quad 1600 \quad 1400 \quad 1200 \quad 1000 \quad 800 \quad 600 \quad 400$

Wavenumber $\left(\mathrm{cm}^{-1}\right)$

Fig. 5 FT-IR spectra in the range of $300-2000 \mathrm{~cm}^{-1}$ for (a) CR, (b) CB[7], (c) CR@CB[7](RT), (d) $C R @ C B[7](100)$, (e) CB[8], (f) CR@CB[8](RT), and (g) CR@CB[8](100). CR bands at 1043 and $1612 \mathrm{~cm}^{-1}$ are indicated with arrows.

The protonation mechanism of CR has been well studied due to its use as an acid-base indicator and as a histological stain for amyloid proteins. ${ }^{33,34}$ Protonation of CR in water occurs below a $\mathrm{pH}$ of 5.3 and has been proposed to give an ammonium form (II) and a resonance-stabilised azonium form (III), which are in tautomeric equilibrium (Scheme 1)..$^{33,53}$ The colour transition from red to blue has been associated with the formation of resonant quinoid structures. In the synthesis of CR@CB[7](RT), the mother liquor had a final $\mathrm{pH}$ of $5-6$ and therefore the exclusive presence of the anionic form (I) in the isolated adduct is not surprising. Performing the synthesis under hydrothermal conditions $\left(100^{\circ} \mathrm{C}\right)$ with a $50 \%$ excess of $\mathrm{CB}$ [7] gave an adduct containing a mixture of the unprotonated and protonated (ammonium and/or azonium) forms of $\mathrm{CR}$, with the former probably being the major form present. Since the as-prepared $\mathrm{CB}[8]$ sample had a much higher $\mathrm{HCl}$ content (ca. 3 equivalents) than $\mathrm{CB}[7]$, the synthesis of $\mathrm{CR} @ \mathrm{CB}[8](\mathrm{RT})$ led to a mother liquor with a $\mathrm{pH}$ of 2-3, and the Raman spectrum of the isolated 
adduct indicates that a higher proportion of quinoid structures is present (Fig. 6(g)). The Raman spectrum of the sample prepared under hydrothermal conditions, CR@CB[8](100), is consistent with an even higher proportion of quinoid structures (Fig. 6(h)). The prevalence of the protonated or unprotonated forms of $\mathrm{CR}$ in the $\mathrm{CR} @ \mathrm{CB}[n]$ adducts was indicated by the colours of the isolated solids since the $\mathrm{CB}$ [7] compounds were dark red while the $\mathrm{CB}[8]$ compounds were purple.

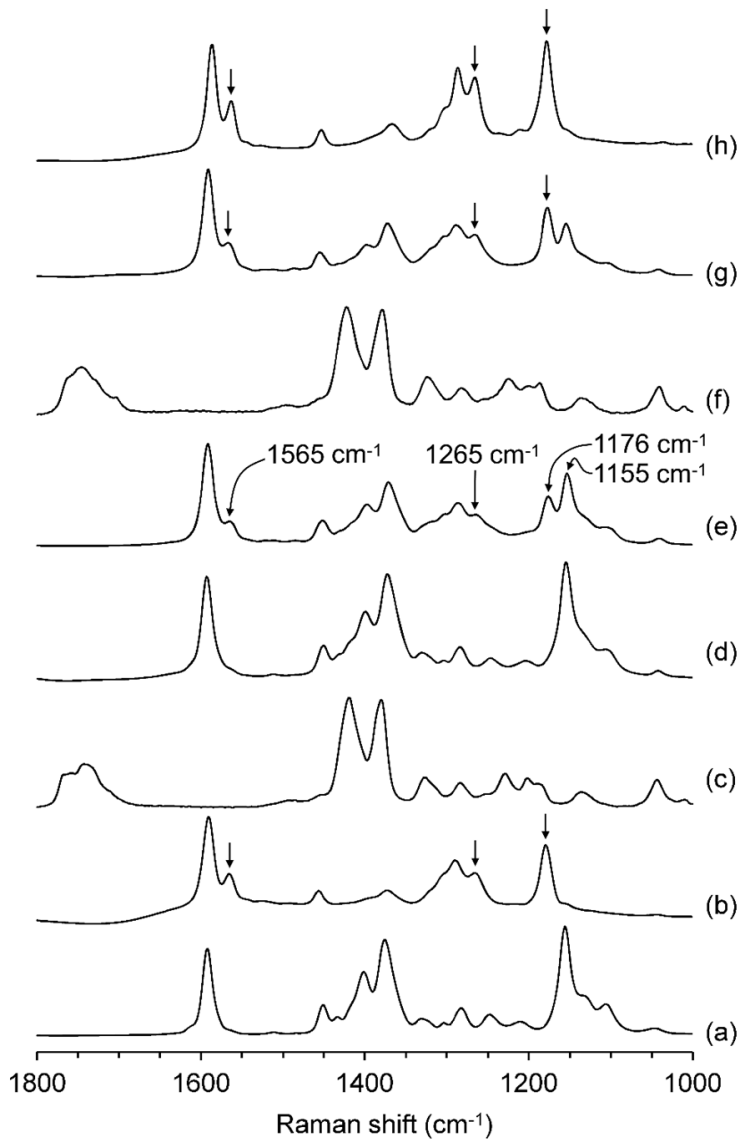

Fig. 6 FT-Raman spectra in the range of $1000-1800 \mathrm{~cm}^{-1}$ for (a) CR, (b) PrCR, (c) CB[7], (d) CR@CB[7](RT), (e) CR@CB[7](100), (f) CB[8], (g) CR@CB[8](RT), and (h) CR@CB[8](100). The bands at 1176,1265 and $1565 \mathrm{~cm}^{-1}$ in spectrum (e) are attributed to $\operatorname{PrCR}$; corresponding bands in spectra $(b, g, h)$ are indicated with arrows.

The trends observed in the Raman spectra regarding the relative proportions of the azoic and resonance-stabilised azonium forms of $\mathrm{CR}$ are consistent with the different residual $\mathrm{Na}_{2} \mathrm{SO}_{4}$ masses registered in the TGA curves of the adducts. Notably, the lack of any residue for CR@CB[8](100) (0 mass\% at $750{ }^{\circ} \mathrm{C}$ ) indicates that the as-synthesised adduct only contained a protonated form of $\mathrm{CR}$ (i.e., containing no sodium ions). On the basis of the 23 mass $\%$ value obtained at $750{ }^{\circ} \mathrm{C}$ in the TGA curve of pure $\mathrm{CR}$, the relative proportions of the unprotonated anionic and protonated ammonium and/or azonium forms of $C R$ can be estimated for the different adducts: 1:0 for CR@CB[7](RT), 0.85:0.15 for CR@CB[7](100), 0.35:0.65 for $C R @ C B[8](R T)$, and 0:1 for CR@CB[8](100). This trend aligns well with the different relative intensities displayed by each adduct for the Raman vibrational bands assigned to the azoic/azonium forms of CR.

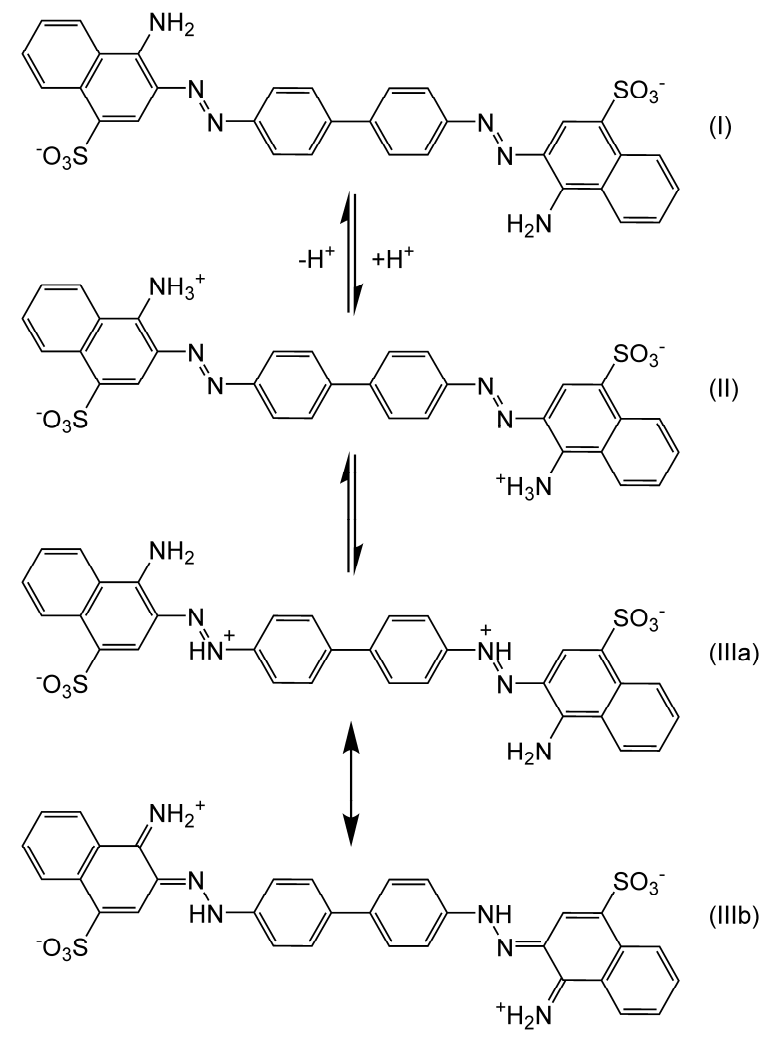

Scheme 1 Protonation mechanism for CR in acidic solution ${ }^{33,52}$ : Anionic form (I), ammonium tautomer (II), azonium tautomer (IIla) and its resonant quinoid structure (IIIb).

${ }^{13} \mathrm{C}\left\{{ }^{1} \mathrm{H}\right\}$ CP MAS NMR spectra for the CR@CB $[n]$ adducts were consistent with other measurements in indicating that on going from $\mathrm{CR} @ \mathrm{CB}[n](\mathrm{RT})$ to $\mathrm{CR} @ \mathrm{CB}[n](100)$ the $\mathrm{CR}$ content decreases as does the relative proportion of the unprotonated form of CR. The spectra are presented and discussed in the ESI ${ }^{+}$.

\section{Photophysical data for CR@CB[n] adducts}

Electronic spectra were obtained for the samples CR@CB[7](100) and CR@CB[8](100). The reader is referred to ref. 54 for a detailed analysis of the absorption, fluorescence, and fluorescence excitation spectra of CR in solution (water or dimethylsulfoxide) and in the solid-state (as the disodium salt or intercalated in a layered double hydroxide host).

The UV-Vis (200-1000 nm) and near-IR (NIR; 1000-2500 nm) absorption spectra of the solid samples CR@CB[n](100) are shown in Fig. 7, and compared with those for $\mathrm{CR}$, $\operatorname{PrCR}$ and $\mathrm{CB}[n]$ in the solid-state, and $C R$ in aqueous solution. In the UV-Vis range, where electronic transitions for the two free cucurbiturils are absent (with the exception of shoulders at $\sim 250 \mathrm{~nm}$ for $\mathrm{CB}[8]$ and $\sim 280 \mathrm{~nm}$ for $\mathrm{CB}[7]$ ), three bands are observed in the spectra of the adducts with maxima at 349, 505 and $725 \mathrm{~nm}$ for CR@CB[7](100), and at 349, 527 and $750 \mathrm{~nm}$ for

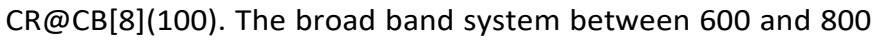
$\mathrm{nm}$ is absent for CR in water at neutral pH. Pigorsch et al. measured absorption spectra of aqueous $\mathrm{CR}$ solutions as a function of $\mathrm{pH}^{33}$ At neutral $\mathrm{pH}$, the solution is orange-red, and the principal absorption band has a maximum at $497 \mathrm{~nm}$ and is assigned to a $\pi-\pi^{*}$ transition of the azo group. As the $\mathrm{pH}$ is 
lowered to 5.3, the solution turns violet, the $497 \mathrm{~nm}$ band shifts slightly to $520 \mathrm{~nm}$, and new overlapping broad bands appear with maxima at 665 and $730 \mathrm{~nm} \cdot{ }^{33,54}$ Pigorsch et al. assigned the absorption band at $520 \mathrm{~nm}$ to the ammonium form (II in Scheme 1 ), which preserves the azoic structure (and thus the band is not shifted far from the corresponding band for unprotonated $C R$ at neutral $\mathrm{pH}$ ), while the band system between 600 and $800 \mathrm{~nm}$ was assigned to the protonated azonium form of CR (III in Scheme 1), where the formation of a quinoid structure causes an absorption at longer wavelengths. We may therefore attribute the absorption maxima at 527 and $750 \mathrm{~nm}$ for CR@CB[8](100) to the protonated ammonium and azonium forms, respectively. This assignment is in accordance with the similarity of the absorption spectra for CR@CB[8](100) and PrCR in the solid-state (Fig. 7A). For CR@CB[7](100), the broad band system between 600 and $800 \mathrm{~nm}$ is relatively less intense than that for the $\mathrm{CB}[8]$ adduct, and the absorption maximum for the band associated with the azoic structure appears at the shorter wavelength of $505 \mathrm{~nm}$. The latter broad band probably comprises overlapping bands due to the unprotonated anionic form of CR ( 497 $\mathrm{nm})$ and the protonated ammonium form $(\sim 527 \mathrm{~nm})$. Hence, the absorption spectra for the CR@CB[n] adducts are consistent with the other characterisation data discussed above, showing that CR@CB[7](100) contains a mixture of the unprotonated anionic and protonated (ammonium/azonium) forms of CR, while CR@CB[8](100) only contains the latter.
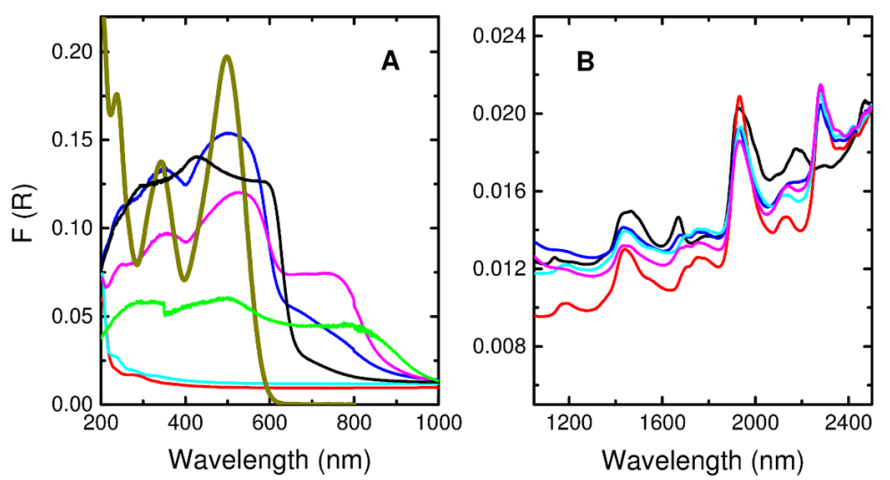

Fig. 7 Diffuse reflectance absorbance spectra (Kubelka-Munk scale) in the UV-Vis (A) and NIR (B) ranges for CR (black), PrCR (green), CB[7] (red), CR@CB[7](100) (blue), CB[8] (cyan), and CR@CB[8](100) (magenta). The absorption spectrum of CR in water (dark yellow) is shown for comparison.

In the NIR range (Fig. 7B), the spectra for $\mathrm{CB}[7]$ and $\mathrm{CB}[8]$ are practically identical, showing bands assigned ${ }^{55}$ to the second overtone of the methylene $\mathrm{C}-\mathrm{H}$ stretching vibration $(1182 \mathrm{~nm}$, $8460 \mathrm{~cm}^{-1}$ ), a combination band involving the symmetric and asymmetric stretching modes of water molecules (1432 nm, $\left.6983 \mathrm{~cm}^{-1}\right)$, the first overtone of the methylene $\mathrm{C}-\mathrm{H}$ stretching vibration (1745 nm, $5731 \mathrm{~cm}^{-1}$ ), and a combination band of O$\mathrm{H}$ stretching and $\mathrm{HOH}$ bending modes $\left(1935 \mathrm{~nm}, 5168 \mathrm{~cm}^{-1}\right)$. The assignment of two other bands at longer wavelengths is less clear; the band at $2125 \mathrm{~nm}\left(4706 \mathrm{~cm}^{-1}\right)$ may be due to a combination of $\mathrm{C}-\mathrm{H}$ and $\mathrm{C}=\mathrm{O}$ stretching modes, while the stronger band at $2280 \mathrm{~nm}\left(4386 \mathrm{~cm}^{-1}\right)$ may be due to a combination of $\mathrm{C}-\mathrm{H}$ stretching and $\mathrm{CH}_{2}$ deformation modes.
These six bands for the $\mathrm{CB}[n]$ molecules are present in the spectra of the CR@CB[n](100) adducts and are essentially unshifted. In fact, the spectra of the pure $\mathrm{CB}[n]$ molecules and the respective adducts are very similar, although careful comparison of these spectra with that for $C R$ in the solid-state reveals the presence of some additional bands for the adducts that can be assigned to the organic dye molecule. In the region 1300-1750 $\mathrm{nm}$, pure CR displays two bands with absorption maxima at $1465 \mathrm{~nm}\left(6826 \mathrm{~cm}^{-1}\right)$ and $1667 \mathrm{~nm}\left(6000 \mathrm{~cm}^{-1}\right)$, which are tentatively assigned to the first overtones of $\mathrm{N}-\mathrm{H}$ and aromatic $\mathrm{C}-\mathrm{H}$ stretching vibrations, respectively. The former band is just visible as a weak shoulder in the spectra of the adducts, while the latter band is more prominent, especially for the adduct CR@CB[7](100).

The fluorescence emission data for CR@CB[7](100) show that while the supramolecular interaction of $\mathrm{CR}$ with $\mathrm{CB}$ [7] does not lead to improved emission properties, it does lead to a blueshift of the emission band from $680 \mathrm{~nm}$ for CR itself to around $655 \mathrm{~nm}$ for the adduct (Fig. 8).

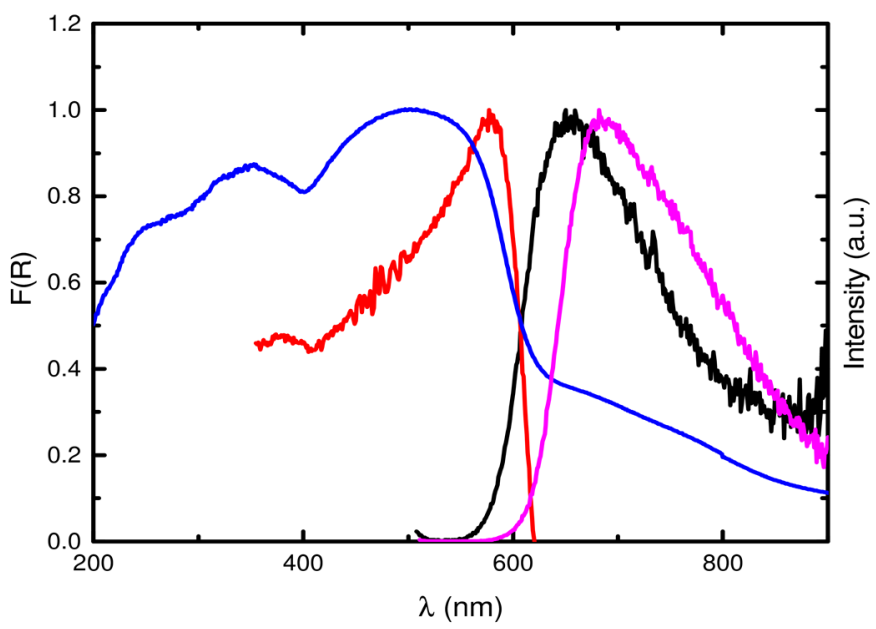

Fig. 8 Absorption (blue), fluorescence excitation ( $\mathrm{red}, \lambda_{\mathrm{em}}=650 \mathrm{~nm}$ ) and emission spectra (black, $\lambda_{\text {exc }}=490 \mathrm{~nm}$ ) of CR@CB[7](100). The emission spectrum of CR in the solid state is shown for comparison (magenta, $\lambda_{\mathrm{exc}}=490 \mathrm{~nm}$ ).

\section{Conclusions}

The mechanism by which cucurbiturils decolourise an aqueous solution of the azo dye Congo red is of interest, especially from the perspective of using $\mathrm{CB}[n]$ to remove $\mathrm{CR}$ and related dyes from wastewater. In the present work, we have shown that ESIMS is an effective technique to investigate $\mathrm{CR}-\mathrm{CB}[n]$ interactions in the gas phase and can distinguish between the formation of host-guest inclusion complexes and outer-surface adducts. The data show that $\mathrm{CR}$ forms the latter type of complex with $\mathrm{CB}$ [7] and $\mathrm{CB}[8]$. The major operative interactions are likely to be $\pi-\pi$ interactions of the carbonyl groups of $\mathrm{CB}[n]$ with the aromatic rings of $\mathrm{CR}$, and $\mathrm{CH} \cdots \mathrm{O}$ hydrogen bonds involving the sulfonate oxygen atoms and $\mathrm{CH}$ or $\mathrm{CH}_{2}$ groups on the periphery of $\mathrm{CB}[n]$ molecules. The combined effect of these interactions is sufficiently strong to result in the removal of CR from aqueous solution through the formation of insoluble exclusion compounds, also known as lattice inclusion compounds. Depending on the type of $\mathrm{CB}[n]$ homologue and the reaction 
conditions $(\mathrm{pH}$, temperature), different forms of $\mathrm{CR}$ can be immobilised, from the unprotonated dianion to the protonated neutral molecule as the ammonium and/or azonium tautomers, the latter of which is stabilised through resonance with a quinoid structure.

\section{Conflicts of interest}

There are no conflicts to declare.

\section{Acknowledgements}

This study had the support of national funds provided by the FCT (Portuguese Foundation for Science and Technology) and MCTES (Portuguese Ministry of Science, Technology and Higher Education) through the strategic projects CICECO - Aveiro Institute of Materials (UID/CTM/50011/2019), CCMAR (UID/Multi/04326/2019) and the Coimbra Chemistry Centre (UID/QUI/UI0313/2014). We are grateful for funding provided through the operational programmes CRESC Algarve 2020 and COMPETE 2020 (project EMBRC.PT ALG-01-0145-FEDER022121), and CENTRO 2020 (project CENTRO-01-0145-FEDER028031, PTDC/QUI-QOR/28031/2017), co-financed by national funds through the FCT/MEC and the European Union through the European Regional Development Fund under the Portugal 2020 Partnership Agreement.

\section{Notes and references}

1 J. Lagona, P. Mukhopadhyay, S. Chakrabarti and L. Isaacs, The Cucurbit[n]uril Family, Angew. Chem. Int. Ed., 2005, 44, 48444870.

2 E. Masson, X. Ling, R. Joseph, L. Kyeremeh-Mensah and X. Lu, Cucurbituril chemistry: a tale of supramolecular success, RSC Adv., 2012, 2, 1213-1247.

3 K.I. Assaf and W.M. Nau, Cucurbiturils: from synthesis to highaffinity binding and catalysis, Chem. Soc. Rev., 2015, 44, 394418.

4 H. Cong, X.L. Ni, X. Xiao, Y. Huang, Q.-J. Zhu, S.-F. Xue, Z. Tao, L.F. Lindoy and G. Wei, Synthesis and separation of cucurbit[n]urils and their derivatives, Org. Biomol. Chem., 2016, 14, 4335-4364.

5 R. Behrend, E. Meyer and F. Rusche, I. Ueber Condensationsproducte aus Glycoluril und Formaldehyd, Justus Liebigs Ann. Chem., 1905, 339, 1-37.

6 W.A. Freeman, W.L. Mock and N.-Y. Shih, Cucurbituril, J. Am. Chem. Soc., 1981, 103, 7367-7368.

7 J. Kim, I.-S. Jung, S.-Y. Kim, E. Lee, J.-K. Kang, S. Sakamoto, K. Yamaguchi and K. Kim, New Cucurbituril Homologues: Syntheses, Isolation, Characterization, and X-ray Crystal Structures of Cucurbit[n]uril ( $n=5,7$, and 8), J. Am. Chem. Soc., 2000, 122, 540-541.

8 A. Day, A.P. Arnold, R.J. Blanch and B. Snushall, Controlling Factors in the Synthesis of Cucurbituril and Its Homologues, J. Org. Chem., 2001, 66, 8094-8100.

9 A.I. Day, R.J. Blanch, A.P. Arnold, S. Lorenzo, G.R. Lewis and I. Dance, A Cucurbituril-Based Gyroscane: A New Supramolecular Form, Angew. Chem. Int. Ed., 2002, 41, 275277.

10 S. Liu, P.Y. Zavalij and L. Isaacs, Cucurbit[10]uril, J. Am. Chem. Soc., 2005, 127, 16798-16799.

11 X.-J. Cheng, L.-L. Liang, K. Chen, N.-N. Ji, X. Xiao, J.-X. Zhang, Y.-Q. Zhang, S.-F. Xue, Q.-J. Zhu, X.-L. Ni and Z. Tao, Twisted Cucurbit[14]uril, Angew. Chem. Int. Ed., 2013, 52, 7252-7255.
12 Q. Li, S.-C. Qiu, J. Zhang, K. Chen, Y. Huang, X. Xiao, Y. Zhang, F. Li, Y.-Q. Zhang, S.-F. Xue, Q.-J. Zhu, Z. Tao, L.F. Lindoy and G. Wei, Twisted Cucurbit[n]urils, Org. Lett., 2016, 18, 4020-4023.

13 W.L. Mock, Cucurbituril, in Supramolecular Chemistry II - Host Design and Molecular Recognition, ed. E. Weber, Top. Curr. Chem., Springer, Berlin, Heidelberg, 1995, vol. 175, pp. 1-24.

14 R. Hoffmann, W. Knoche, C. Fenn and H.-J. Buschmann, Hostguest complexes of cucurbituril with the 4methylbenzylammonium ion, alkali-metal cations and $\mathrm{NH}_{4}{ }^{+}, J$. Chem. Soc. Faraday Trans., 1994, 90, 1507-1511.

15 S.J. Barrow, S. Kasera, M.J. Rowland, J. del Barrio and O.A. Scherman, Cucurbituril-Based Molecular Recognition, Chem. Rev., 2015, 115, 12320-12406.

16 D. Das, K.I. Assaf and W.M. Nau, Applications of Cucurbiturils in Medicinal Chemistry and Chemical Biology, Front. Chem., 2019, 7, art. no. 619.

17 D.P. Buck, P.M. Abeysinghe, C. Cullinane, A.I. Day, J.G. Collins and M.M. Harding, Inclusion complexes of the antitumour metallocenes $\mathrm{Cp}_{2} \mathrm{MCl}_{2}(\mathrm{M}=\mathrm{Mo}, \mathrm{Ti})$ with cucurbit[n]urils, Dalton Trans., 2008, 2328-2334.

18 C.I.R. Magalhães, A.C. Gomes, A.D. Lopes, I.S. Gonçalves, M. Pillinger, E. Jin, I. Kim, Y.H. Ko, K. Kim, I. Nowik and R.H. Herber, Ferrocene and ferrocenium inclusion compounds with cucurbiturils: a study of metal atom dynamics probed by Mössbauer spectroscopy, Phys. Chem. Chem. Phys., 2017, 19, 21548-21555.

19 R.N. Dsouza, U. Pischel and W.M. Nau, Fluorescent Dyes and Their Supramolecular Host/Guest Complexes with Macrocycles in Aqueous Solution, Chem Rev., 2011, 111, 7941-7980.

20 A.C. Bhasikuttan and H. Pal, J. Mohanty, Cucurbit $[n]$ uril based supramolecular assemblies: tunable physico-chemical properties and their prospects, Chem. Commun., 2011, 47, 9959-9971.

21 O.A. Gerasko, M.N. Sokolov and V.P. Fedin, Mono- and polynuclear aqua complexes and cucurbit[6]uril: Versatile building blocks for supramolecular chemistry, Pure Appl. Chem., 2004, 76, 1633-1646.

22 X.-L. Ni, X. Xiao, H. Cong, L.-L. Liang, K. Cheng, X.-J. Cheng, N.N. Ji, Q.-J. Zhu, S.-F. Xue and Z. Tao, Cucurbit[n]uril-based coordination chemistry: from simple coordination complexes to novel poly-dimensional coordination polymers, Chem. Soc. Rev., 2013, 42, 9480-9508.

23 J. Lü, J.-X. Lin, M.-N. Cao and R. Cao, Cucurbituril: A promising organic building block for the design of coordination compounds and beyond, Coord. Chem. Rev., 2013, 257, 13341356.

24 X.-L. Ni, X. Xiao, H. Cong, Q.-J. Zhu, S.-F. Xue and Z. Tao, SelfAssemblies Based on the "Outer-Surface Interactions" of Cucurbit[n]urils: New Opportunities for Supramolecular Architectures and Materials, Acc. Chem. Res., 2014, 47, 13861395.

25 M. Zhang, R.-L. Lin, W.-Q. Sun and J.-X. Liu, Anion encapsulation and complexation by cucurbit[n]urils and their derivatives, J. Incl. Phenom. Macro. Chem., 2018, 90, 173-187.

26 K. Chen, Y.-S. Kang, Y. Zhao, J.-M. Yang, Y. Lu and W.-Y. Sun, Cucurbit[6]uril-Based Supramolecular Assemblies: Possible Application in Radioactive Cesium Cation Capture, J. Am. Chem. Soc., 2014, 136, 16744-16747.

27 B.D. Wagner and A.I. MacRae, The Lattice Inclusion Compound of 1,8-ANS and Cucurbituril: A Unique Fluorescent Solid, J. Phys. Chem. B, 1999, 103, 10114-10119.

28 B.D. Wagner, N. Stojanovic, A.I. Day and R.J. Blanch, Host Properties of Cucurbit[7]uril: Fluorescence Enhancement of Anilinonaphthalene Sulfonates, J. Phys. Chem. B, 2003, 107, 10741-10746. 
29 L. Liu, Z. Zhao and C. Hao, 3D fluorescent cucurbit[7]uril framework linked by anion fluorophore, J. Incl. Phenom. Macrocycl. Chem. 2017, 88, 247-252.

30 X. Gao, Z. Xu, M. Liu and P. Zhang, A novel CB[6]-based supramolecular assembly exhibiting highly selective multiresponsive fluorescence sensing for trace amounts of $\mathrm{Fe}^{3+}$ ions and acetone molecules, J. Solid State Chem., 2019, 271, 110-114.

31 D.P. Steensma, "Congo" Red. Out of Africa? Arch. Pathol. Lab. Med., 2001, 125, 250-252.

32 C.J. Cooksey, Quirks of dye nomenclature. 2. Congo red, Biotech. Histochem., 2014, 89, 384-387.

33 E. Pigorsch, A. Elhaddaoui and S. Turrell, Spectroscopic study of $\mathrm{pH}$ and solvent effects on the structure of Congo red and its binding mechanism to amyloid-like proteins, Spectrochim. Acta A Mol. Biomol. Spectrosc., 1994, 2145-2152.

34 E.I. Yakupova, L.G. Bobyleva, I.M. Vikhlyantsev and A.G. Bobylev, Congo Red and amyloids: history and relationship, Biosci. Rep., 2019, 39, art. no. BSR20181415.

35 M. Hernández-Zamora, F. Martínez-Jerónimo, E. CristianiUrbina and R.O. Cañizares-Villanueva, Congo red dye affects survival and reproduction in the cladoceran Ceriodaphnia dubia. Effects of direct and dietary exposure, Ecotoxicology, 2016, 25, 1832-1840.

36 M. Hernández-Zamora and F. Martínez-Jerónimo, Congo red dye diversely affects organisms of different trophic levels: a comparative study with microalgae, cladocerans, and zebrafish embryos, Environ. Sci. Pollut. Res., 2019, 26, 1174311755.

37 N.P. Raval, P.U. Shah and N.K. Shah, Adsorptive amputation of hazardous azo dye Congo red from wastewater: a critical review, Environ. Sci. Pollut. Res., 2016, 23, 14810-14853.

38 S. Karcher, A. Kornmüller and M. Jekel, Removal of Reactive Dyes by Sorption/Complexation with Cucurbituril, Water Sci. Technol., 1999, 40, 425-433.

39 H.J. Nagy, P. Sallay, M.L. Varga, I. Rusznák, P. Bakó and A. Víg, Removal of Dyes from Industrial Wastewater by Cucurbiturils, Text. Res. J., 2009, 79, 1312-1318.

40 X. Xie, X. Li, H. Luo, H. Lu, F. Chen and W. Li, The Adsorption of Reactive Blue 19 Dye onto Cucurbit[8] uril and Cucurbit[6]uril: An Experimental and Theoretical Study, J. Phys. Chem. B, 2016, 120, 4131-4142.

41 X. Li, X. Xie, H. Luo, L. Li, Z. Li, Z. Xue and W. Li, Adsorption of reactive yellow $X-R G$ and reactive brilliant red $X-3 B$ onto cucurbit[8]uril and cucurbit[6]uril: Effect factors, adsorption behavior and mechanism study, J. Colloid Interface Sci., 2017, 498, 31-46.

42 H. Luo, X. Huang, Y. Luo, Z. Li, L. Li, C. Gao, J. Xiong and W. Li, Adsorption behavior and mechanism of acidic blue 25 dye onto cucurbit[8]uril: A spectral and DFT study, Spectrochim. Acta A Mol. Biomol. Spectrosc., 2018, 193, 125-132.

43 P. Zhang, X. Gao, M. Liu, L. Liang, H. Li and Y. Wang, The effective adsorption of Reactive Blue 19 Dye with a cucurbit[6]uril based supramolecular assembly, Inorg. Chem. Commun., 2018, 96, 13-15.

44 S.M. Bruno, A.C. Gomes, T.S.M. Oliveira, M.M. Antunes, A.D. Lopes, A.A. Valente, I.S. Gonçalves and M. Pillinger, Catalytic alcoholysis of epoxides using metal-free cucurbituril-based solids, Org. Biomol. Chem., 2016, 14, 3873-3877.

45 A.C. Gomes, C.I.R. Magalhães, T.S.M. Oliveira, A.D. Lopes, I.S. Gonçalves and M. Pillinger, Solid-state study of the structure and host-guest chemistry of cucurbituril-ferrocene inclusion complexes, Dalton Trans., 2016, 45, 17042-17052.

46 J. Seixas de Melo, T. Costa, A. Francisco, A.L. Maçanita, S. Gago and I.S. Gonçalves, Dynamics of short as compared with long poly(acrylic acid) chains hydrophobically modified with pyrene, as followed by fluorescence techniques, Phys. Chem. Chem. Phys., 2007, 9, 1370-1385.
47 M. Pessêgo, J. Mendoza, J.P. Da Silva, N. Basílio, L. Garcia-Rio, Unveiling the Formation 1:2 Supramolecular Complexes Between Cucurbit[7]uril and a Cationic Calix[4]arene Derivative, Chem. Commun., 2019, 55, 13828-13831.

48 J.P. Da Silva, N. Jayaraj, S. Jockusch, N.J. Turro and V. Ramamurthy, Aggregates of Cucurbituril Complexes in the Gas Phase, Org. Lett., 2011, 13, 2410-2413.

49 M.A.A. Rodrigues, D.C. Mendes, V. Ramamurthy and J.P. Da Silva, ESI-MS of Cucurbituril Complexes Under Negative Polarity, J. Am. Soc. Mass Spectrom., 2017, 28, 2508-2514.

50 S. Kobayashi, S. Miwa, I. Tanaka, K. Mikuni, M. Miura, S. Ogawa, K. Takahashi, Dospectral Analyses of Interaction between Congo Red and Cyclodextrins at Various pH, J. Appl. Glycosci., 2008, 55, 173-177.

51 L. Liu, Y. Yao, X. Zhang, C. Hao, A Fluorescent 1,5Naphthalenedisulfonate Anion-Linked Cucurbit[6]uril Framework, Eur. J. Org. Chem., 2015, 6806-6810.

52 Z. Yermiyahu, A. Landau, A. Zaban, I. Lapides and S. Yariv, Monoionic montmorillonites treated with Congo red, J. Therm. Anal. Calorim., 2003, 72, 431-441.

53 Z. Yermiyahu, I. Lapides and S. Yariv, Thermo-visibleabsorption spectroscopy study of the protonated Congo-red montmorillonite complex, Appl. Clay Sci., 2007, 37, 1-11.

54 A.L. Costa, A.C. Gomes, M. Pillinger, I.S. Gonçalves, J. Pina and J.S. Seixas de Melo, Insights into the photophysics and supramolecular organization of Congo red in solution and the solid state, ChemPhysChem, 2017, 18, 564-575.

$55 \mathrm{~J}$. Workman, Jr. and L. Weyer, Practical Guide to Interpretive Near-Infrared Spectroscopy, CRC Press, Taylor \& Francis Group, Boca Raton, 2008. 


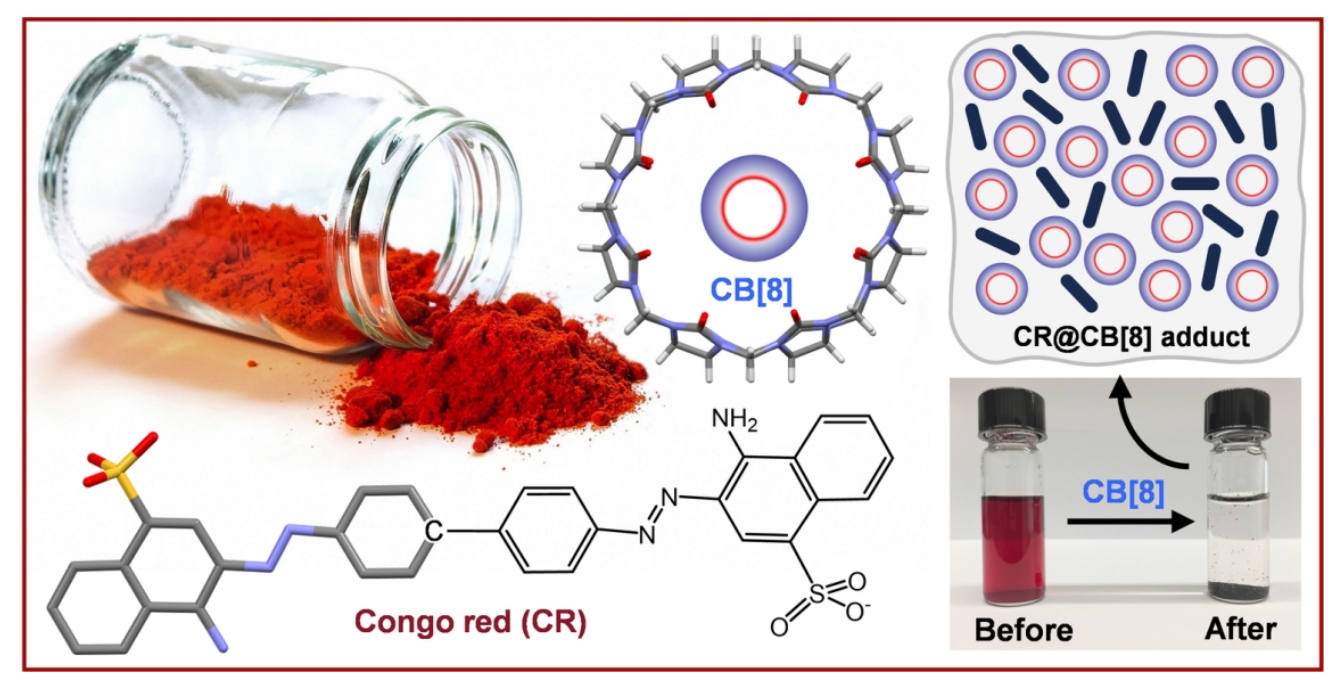

$129 \times 65 \mathrm{~mm}(300 \times 300$ DPI $)$ 